\title{
Experience with International Neuroblastoma Staging System and Pathology Classification
}

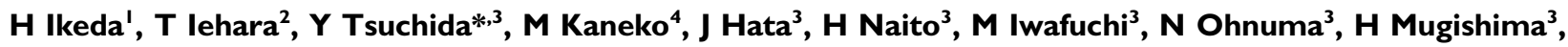

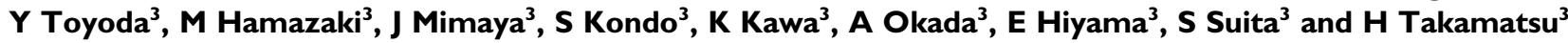 \\ 'Department of Pediatric Surgery, Dokkyo University School of Medicine, Koshigaya Hospital, 2-I-50 Minami-Koshigaya, Koshigaya, Saitama 343-8555, Japan; \\ ${ }^{2}$ Department of Pediatrics, Kyoto Prefectural University of Medicine, Hirokohji, Kawaramachi-dori, Kamigyo-ku, Kyoto 602-8566, Japan; ${ }^{3}$ Study Group of \\ Neuroblastoma, Gunma Children's Medical Center, 377 Shimohakoda, Hokkitsu, Seta-gun, Gunma 377-8577, Japan; ${ }^{4}$ Department of Pediatric Surgery, \\ University of Tsukuba, I-I-I Tennodai, Tsukuba 305-8575, Japan
}

The International Neuroblastoma Staging System and Pathology Classification were proposed in 1988 and in 1999, respectively, but their clinical value has not yet been fully studied in new patients. Six hundred and forty-four patients with neuroblastoma treated between January 1995 and December 1999 were analysed by these classifications. The 4-year overall survival rate of patients $<12$ months of age with INSS stages I, 2A, 2B, 3 and 4 S disease was $98.5 \%$, which was significantly higher than the $73.1 \%$ rate in stage 4 patients $<12$ months $(P<0.000 \mathrm{I})$. When patients were $\geqslant 12$ months, the 4 -year overall survival rate of patients with neuroblastoma at I, 2A, 2B and 3 stages was $100 \%$ and that of patients at stage 4 was $48.5 \%(P<0.000 \mathrm{I})$. As to the International Neuroblastoma Pathology Classification histology, the 4-year overall survival rate was $98.8 \%$ in patients with favourable histology and $60.7 \%$ in those with unfavourable histology in the $<12$ months group $(P<0.0001)$. In the $\geqslant 12$ months group, the 4-year oral survival of patients with favourable histology was $95.3 \%$ and that of patients with unfavourable histology was 50.6\% $(P<0.000 \mathrm{I})$. Among biological factors, MYCN amplification, DNA diploidy and I $\mathrm{p}$ deletions were significantly associated with poor prognosis in patients $<12$ months, as were MYCN amplification and DNA diploidy in patients $\geqslant 12$ months of age. Multivariate analysis showed that the INSS stage (stage 4 vs other stages) and International Neuroblastoma Pathology Classification histology (unfavourable vs favourable) were significantly and independently associated with the survival of patients undergoing treatment, stratified by age, stage and MYCN amplification ( $P=0.0002$ and $P=0.005 \mathrm{I}$, respectively). British Journal of Cancer (2002) 86, I I I0- | | I6. DOI: 10.1038/sj/bjc/660023I www.bjcancer.com (C) 2002 Cancer Research UK

Keywords: neuroblastoma; International Neuroblastoma Staging System (INSS); International Neuroblastoma Pathology Classification (INPC); MYCN amplification; DNA ploidy; Ip deletion

International cooperative groups have developed new classifications of neuroblastoma risk groups to compare treatment results internationally and seek effective means to deal with neuroblastoma, particularly in advanced stages. The International Neuroblastoma Staging System (INSS) was originally proposed in 1988, and revised in 1993 (Brodeur et al, 1993). Since then the INSS has been used worldwide (Castleberry et al, 1994; Kaneko et al, 1998), replacing the previous staging systems of different groups. The International Neuroblastoma Pathology Classification (INPC) that is fundamentally based on Shimada's classification was also proposed in 1999 to provide neuroblastoma study groups with a common language (Shimada et al, 1999). However, the clinical importance of these classifications has never been extensively evaluated; Castleberry et al (1994) applied the INSS only retrospectively for their patients treated between 1981 and 1990. Since the predictability of prognostic factors often depends on the intensity or efficacy of treatment, it is important to examine the value of these risk classifications in a

*Correspondence: Y Tsuchida, Department of Surgery, Gunma Children's Medical Center, 779 Shimohakota, Hokkitsu, Seta-gun, Gunma 377-8577, Japan; E-mail: tuchida@gcmc.pref.gunma.jp

Received 5 October 200 I; revised 4 February 2002; accepted II February 2002 study in which highly effective modern treatments are applied (Kawa et al, 1999; Matthay et al, 1999).

Clinical results achieved prior to 1991 by us and by others (Brodeur et al, 1984; Seeger et al, 1985; Sawaguchi et al, 1990) clearly showed that patients with $M Y C N$-amplified tumours have a worse prognosis than those without. It was therefore decided in Japan in 1991 to administer intensive induction chemotherapy with a double dose of cyclophosphamide to high-risk patients with MYCN amplification (Kaneko et al, 1998), and that strategy resulted in improved clinical results (Kawa et al, 1999). In the present study we examined the prognostic value of the INSS, the INPC and biological factors including MYCN amplification, DNA ploidy and $1 \mathrm{p}$ deletion in patients with neuroblastoma who underwent treatment between 1995 and 1999.

\section{PATIENTS AND METHODS}

A total of 731 patients with newly diagnosed neuroblastoma whose treatment was started between January 1995 and December 1999 were retrospectively reviewed. Patients $\geqslant 12$ months of age were treated with the protocols for advanced neuroblastoma in which treatment was stratified by stage and $M Y C N$ amplification status (Kaneko et al, 1998). Stem cell transplantation was performed in $65.4 \%$ of stage 4 patients and in $67.4 \%$ of $M Y C N$-amplified 
patients $\geqslant 12$ months of age. Patients $<12$ months of age were registered with the Japanese Infantile Neuroblastoma Cooperative Study and were treated with the protocols for infant neuroblastoma (Matsumura and Michon, 2000). Briefly, these infant patients were first examined for the presence or absence of $M Y C N$ amplification, and those without amplification were treated with or without chemotherapy based on the INSS stage. Patients with MYCN amplification were treated, like patients $\geqslant 12$ months of age, with combination chemotherapy with or without stem cell transplantation. Stem cell transplantation was carried out in $27.5 \%$ of stage 4 patients and in $41.7 \%$ of $M Y C N$-amplified patients < 12 months of age (Table 1).

Patient information with regard to age, gender, stage, histology and biological characteristics of the tumour including $M Y C N$ amplification, DNA ploidy and $1 p$ deletion was collected from the participating institutions (Appendix). Two pathologists, one of whom was a member of the International Neuroblastoma Pathology Committee, reviewed all of the specimens according to the INPC (Shimada et al, 1999). The MYCN gene copy number was determined by Southern blot hybridisation, and amplification was defined as $\geqslant 10$ copies. DNA content analysis was performed by means of flow cytometry, and tumours were classified into diploid tumours (DNA index=1) and aneuploid tumours (DNA index $\geqslant 1.1$ ). No genes responsible for $M Y C N$ amplification have yet been identified and there is no consensus on the definition of prognostically significant deletions of $1 \mathrm{p}$ so that no single uniform method to detect $1 p$ deletions could be used. The method was therefore left to the discretion of each laboratory, and $1 \mathrm{p}$ deletions were defined as present when karyotypic analysis showed large deletions in the distal region of $1 \mathrm{p}$ or when molecular analysis demonstrated small deletions of $1 \mathrm{p} 36$ by examining the loss of heterozygosity (LOH) with gene markers (Ohtsu et al, 1997).

Patient outcomes were followed up as of 30 September 2000, and the results were obtained in 675 patients. There were 31 patients with screening-detected tumours who had been observed without histological confirmation and definitive treatment. Excluding these 31 patients because of insufficient data, 644 patients, 368 males and 276 females, were included in the final analyses. The age of the patients ranged from 0 to 221 months (median, 8 months), and 485 patients were $<12$ months of age with 159 patients $\geqslant 12$ months.

Differences between the two groups in categorical data were analysed by means of Fisher's exact probability test or the chisquare test. Overall survival was estimated by the Kaplan-Meier method and the difference between the curves was compared with the log-rank test. For multivariate analysis, the Cox regression models were used to identify independent prognostic factors. Statistical analysis was performed with SPSS 7.5J for Windows

Table I Number of patients who received stem cell transplantation according to sub-groups

\begin{tabular}{|c|c|c|c|c|}
\hline \multirow[b]{2}{*}{ Age } & \multirow[b]{2}{*}{ Sub-groups } & \multicolumn{2}{|c|}{$\begin{array}{c}\text { Stem cell } \\
\text { transplantation }\end{array}$} & \multirow[b]{2}{*}{ No information } \\
\hline & & Received & Not-received & \\
\hline \multirow{6}{*}{$\begin{array}{c}<12 \text { months } \\
(n=485)\end{array}$} & Stage I, 2A, 2B, 3, 4S & 3 & 428 & 6 \\
\hline & Stage 4 & II (27.5\%) & 29 & 3 \\
\hline & not determined & 0 & 5 & 0 \\
\hline & MYCN < 10 copies & 9 & 427 & 7 \\
\hline & MYCN $\geqslant 10$ copies & $5(41.7 \%)$ & 7 & 2 \\
\hline & not determined & 0 & 28 & 0 \\
\hline \multirow{5}{*}{$\begin{array}{c}\geqslant 12 \text { months } \\
(n=159)\end{array}$} & Stage I, 2A, 2B, 3 & 4 & 49 & 0 \\
\hline & Stage 4 & $68(65.4 \%)$ & 36 & 2 \\
\hline & MYCN < I0 copies & 35 & 70 & I \\
\hline & MYCN $\geqslant 10$ copies & $31(67.4 \%)$ & 15 & 0 \\
\hline & not determined & 0 & 6 & I \\
\hline
\end{tabular}

Medical Pack (SPSS Inc., Chicago, IL, USA) and a $P$ value of $<0.05$ was considered statistically significant.

\section{RESULTS}

\section{INSS, INPC and biological prognostic factors}

The INSS stage, INPC histology and biological prognostic factors of the 644 patients are shown in Table 2. INSS stage was determined in 639 patients, and there was a significant difference in stage distribution between patients $<12$ months of age and those $\geqslant 12$ months $(P<0.001)$. Among the 480 patients $<12$ months of age, $43(9 \%)$ had stage 4 disease, and there were $106(67 \%)$ stage 4 patients among the 159 patients $\geqslant 12$ months. Histology was evaluated according to the INPC in 556 patients. Of 423 patients $<12$ months of age, favourable histology was diagnosed in 402 patients $(95 \%)$ and unfavourable histology in 21 patients (5\%). Among the 133 patients $\geqslant 12$ months of age, 47 patients (35\%) had favourable histology and 86 patients $(65 \%)$ unfavourable histology. The difference between the two age groups in unfavourable histology was statistically significant $(P<0.001)$.

The occurrence of unfavourable biological characteristics was also significantly different between $<12$ months and $\geqslant 12$ months of age. The MYCN gene copy number was examined in 609 patients. Greater than $\geqslant 10$ copies of $M Y C N$ were observed in 14 $(3 \%)$ of 457 patients $<12$ months of age, and in $46(30 \%)$ of 152 patients $\geqslant 12$ months $(P<0.001)$. DNA content analysis by flow cytometry was carried out in 480 patients and $78(21 \%)$ of 375 patients in the younger age group and $55(52 \%)$ of 105 patients in the older age group had diploid tumours $(P<0.001)$. Chromosomal abnormalities were examined in 361 patients, and the presence of $1 p$ deletions was demonstrated in 24 (9\%) of 262 patients $<12$ months of age and in $29(29 \%)$ of 99 patients $\geqslant 12$ months $(P<0.001)$.

Table 2 INSS, INPC and biological characteristics by age in 644 patients with neuroblastoma

\begin{tabular}{|c|c|c|c|c|}
\hline \multirow[b]{2}{*}{ Characteristics } & \multicolumn{2}{|c|}{ Patient age } & \multirow[b]{2}{*}{ Total } & \multirow[b]{2}{*}{$P$ value } \\
\hline & $\begin{array}{c}<\mid 12 \text { months } \\
(n=485)\end{array}$ & $\begin{array}{c}\geqslant 12 \text { months } \\
(n=159)\end{array}$ & & \\
\hline \multicolumn{5}{|l|}{ INSS } \\
\hline 1 & 217 (45\%) & 26 (16\%) & 243 & \\
\hline $2 \mathrm{~A}$ & $38(8 \%)$ & $5(3 \%)$ & 43 & \\
\hline $2 B$ & $69(14 \%)$ & 7 (4\%) & 76 & $<0.001$ \\
\hline 3 & 73 (I5\%) & $15(9 \%)$ & 88 & \\
\hline 4 & $43(9 \%)$ & 106 (67\%) & 149 & \\
\hline $4 \mathrm{~S}$ & $40(8 \%)$ & & 40 & \\
\hline ND & 5 & & 5 & \\
\hline \multicolumn{5}{|l|}{ INPC } \\
\hline Favourable & 402 (95\%) & 47 (35\%) & 449 & \\
\hline Unfavourable & $21(5 \%)$ & $86(65 \%)$ & 107 & $<0.001$ \\
\hline ND & 62 & 26 & 88 & \\
\hline \multicolumn{5}{|l|}{ MYCN } \\
\hline$<10$ copies & 443 (97\%) & 106 (70\%) & 549 & \\
\hline$\geqslant 10$ copies & $14(3 \%)$ & 46 (30\%) & 60 & $<0.001$ \\
\hline ND & 28 & 7 & 35 & \\
\hline \multicolumn{5}{|l|}{ DNA ploidy } \\
\hline Aneuploidy & 297 (79\%) & 50 (48\%) & 347 & \\
\hline Diploidy & 78 (2।\%) & $55(52 \%)$ & 133 & $<0.001$ \\
\hline ND & 110 & 54 & 164 & \\
\hline \multicolumn{5}{|l|}{ Ip deletion } \\
\hline$-v e$ & 238 (91\%) & 70 (7।\%) & 308 & \\
\hline +ve & $24(9 \%)$ & 29 (29\%) & 53 & $<0.001$ \\
\hline ND & 223 & 60 & 283 & \\
\hline
\end{tabular}

INSS=International Neuroblastoma Staging System; INPC=International Neuroblastoma Pathology Classification; ND=not determined; - ve=negative; +ve=positive. 


\section{Overall survival rates}

The median follow-up for all of the 644 patients was 1120 days, and that for living patients 1179 days. The 2- and 4-year overall survival (2-OS and 4 -OS) rates of patients $<12$ months of age were 96.5 and $96.2 \%$, respectively, and those of patients who were $\geqslant 12$ months of age were 77.6 and $64.6 \%$, respectively. Seventy-five per cent of the patients in this series were $<12$ months of age. To avoid the bias relating to the patient age distribution, the following data analyses were performed in two groups of $<12$ months and $\geqslant 12$ months of age.

The 2-OS and 4-OS rates of the 639 patients are shown according to the INSS stage in Table 3 . There were no differences in the overall survival rates among stages $1,2 \mathrm{~A}, 2 \mathrm{~B}, 3$ and $4 \mathrm{~S}$ patients $<12$ months of age, and none among stages $1,2 \mathrm{~A}, 2 \mathrm{~B}$ and 3 patients $\geqslant 12$ months of age, either. Therefore, infants with stages $1,2 \mathrm{~A}, 2 \mathrm{~B}, 3$ and $4 \mathrm{~S}$ disease in the younger age group, and patients with stages $1,2 \mathrm{~A}, 2 \mathrm{~B}$ and 3 disease in the older age group were combined in the subsequent survival analyses.

Table 3 Two- and four-year overall survival rates by various factors

\begin{tabular}{|c|c|c|c|c|}
\hline \multirow[b]{2}{*}{ Factor } & \multirow[b]{2}{*}{$n$} & \multicolumn{2}{|c|}{$\begin{array}{l}\text { Overall survival rate } \\
\text { (\%) }\end{array}$} & \multirow[b]{2}{*}{$P$ value } \\
\hline & & 2-year & 4-year & \\
\hline \multicolumn{5}{|l|}{ INSS stage } \\
\hline \multicolumn{5}{|l|}{$<12$ months } \\
\hline । & 217 & 99.5 & 99.5 & \\
\hline $2 \mathrm{~A}$ & 38 & 100 & 100 & \\
\hline $2 B$ & 69 & 98.4 & 98.4 & \\
\hline 3 & 73 & 98.6 & 96.3 & $<0.0001$ \\
\hline $4 S$ & 40 & 95.0 & 95.0 & \\
\hline 4 & 43 & 73.1 & 73.1 & \\
\hline \multicolumn{5}{|l|}{$\geqslant 12$ months } \\
\hline I & 26 & 100 & 100 & \\
\hline $2 \mathrm{~A}$ & 5 & 100 & / & \\
\hline $2 B$ & 7 & 100 & 100 & $<0.0001$ \\
\hline 3 & 15 & 100 & 100 & \\
\hline 4 & 106 & 67.3 & 48.5 & \\
\hline \multicolumn{5}{|l|}{ INPC histology } \\
\hline \multicolumn{5}{|l|}{$<12$ months } \\
\hline Favourable & 402 & 98.8 & 98.8 & \\
\hline Unfavourable & 21 & 60.7 & 60.7 & $<0.0001$ \\
\hline \multicolumn{5}{|l|}{$\geqslant 12$ months } \\
\hline Favourable & 47 & 95.3 & 95.3 & \\
\hline Unfavourable & 86 & 70.3 & 50.6 & $<0.0001$ \\
\hline \multicolumn{5}{|l|}{ MYCN } \\
\hline \multicolumn{5}{|l|}{$<12$ months } \\
\hline < 10 copies & 443 & 98.2 & 97.9 & \\
\hline$\geqslant 10$ copies & 14 & 40.8 & 40.8 & $<0.0001$ \\
\hline \multicolumn{5}{|l|}{$\geqslant 12$ months } \\
\hline$<10$ copies & 106 & 83.8 & 72.0 & \\
\hline$\geqslant 10$ copies & 46 & 67.1 & 54.4 & 0.0117 \\
\hline \multicolumn{5}{|l|}{ DNA ploidy } \\
\hline \multicolumn{5}{|l|}{$<12$ months } \\
\hline Aneuploidy & 297 & 98.0 & 98.0 & \\
\hline Diploidy & 78 & 89.2 & 89.2 & 0.0007 \\
\hline \multicolumn{5}{|l|}{$\geqslant 12$ months } \\
\hline Aneuploidy & 50 & 93.4 & 84.2 & 0.0256 \\
\hline Diploidy & 55 & 77.4 & 61.5 & \\
\hline \multicolumn{5}{|l|}{ Ip deletion } \\
\hline \multicolumn{5}{|l|}{$<12$ months } \\
\hline$-v e$ & 238 & 99.2 & 98.6 & \\
\hline$+v e$ & 24 & 82.9 & 82.9 & $<0.0001$ \\
\hline \multicolumn{5}{|l|}{$\geqslant 12$ months } \\
\hline - ve & 70 & 79.6 & 70.1 & \\
\hline$+v e$ & 29 & 75.2 & 42.5 & 0.1148 \\
\hline
\end{tabular}

-ve=negative; +ve=positive; /=not enough patients.
In patients $<12$ months of age, the 4 -OS rate of patients in stages $1,2 \mathrm{~A}, 2 \mathrm{~B}, 3$ and $4 \mathrm{~S}$ combined was $98.5 \%$, which was significantly higher than the $73.1 \%$ of patients in stage $4(P<0.0001)$. In patients $\geqslant 12$ months of age, the 4 -OS rate of patients in stages 1 , $2 \mathrm{~A}, 2 \mathrm{~B}$ and 3 combined was $100 \%$, whereas that of patients with stage 4 disease was $48.5 \%$; the difference was statistically significant $(P<0.0001)$ (Figure 1).

INPC histology was also shown to be a significant prognostic factor. The 4-OS rate of patients with favourable histology was $98.8 \%$, significantly higher than the rate of $60.7 \%$ for patients with unfavourable histology when the patients were $<12$ months of age $(P<0.0001)$ (Figure 2$)$. The survival rate for patients with favourable histology was $95.3 \%$, significantly higher than the $50.6 \%$ rate for patients with unfavourable histology in patients $\geqslant 12$ months of age $(P<0.0001)$.

Among patients $<12$ months of age, overall survival rates for patients with favourable biological characteristics $(<10$ copies of the MYCN gene, aneuploidy and absence of $1 \mathrm{p}$ deletions) were significantly higher than those for patients with unfavourable characteristics $(\geqslant 10$ copies of the MYCN gene, diploidy and the presence of $1 \mathrm{p}$ deletions) (Figures 3, 4 and 5, respectively) $(P<0.0001, P=0.0007$ and $P<0.0001$, respectively). Of the 14 patients with $M Y C N$ amplification, eight patients had died before this retrospective review, and the 4OS rate was $40.8 \%$.

When the patients were $\geqslant 12$ months of age, MYCN amplification and DNA diploidy were significantly associated with poor prognosis. The 2-OS and 4-OS rates for patients with neuroblastoma with amplified MYCN were 67.1 and $54.4 \%$, respectively, and significantly lower than the 83.8 and $72.0 \%$ for patients without MYCN amplification $(P=0.0117)$. The 2-OS and 4-OS rates for patients with diploid tumour were 77.4 and $61.5 \%$, respectively, which were significantly lower than the 93.4 and $84.2 \%$, respectively, for patients with aneuploid tumour $(P=0.0256)$. In the overall survival rate there was no significant difference between patients with and without $1 \mathrm{p}$ deletion $(P=0.1148)$.

\section{Multivariate analysis of prognostic factors}

A multivariate analysis with Cox regression models was undertaken in 460 patients with complete data including age, INSS stage, INPC histology, MYCN amplification and DNA ploidy (Table 4). 1p deletion was excluded from the analysis because genetic abnormalities of chromosome $1 \mathrm{p}$ were examined in only $361(56.1 \%)$ of 644 patients. The analysis showed that INSS stage and INPC histology were significantly and independently associated with patient survival $(P=0.0002$ and $P=0.0051$, respectively), and that the biological variables, MYCN amplification and DNA ploidy, did not have prognostic significance after correcting for stage and histology by the INSS and INPC.

\section{DISCUSSION}

A protocol with stratification of treatment mainly based on the presence or absence of $M Y C N$ amplification was introduced in our group study in 1991 (Kaneko et al, 1998). This protocol was designed to administer intensive induction chemotherapy with a double dose of cyclophosphamide and to do stem cell transplantation to high-risk patients with MYCN amplification, and analysis of outcomes showed a significantly higher response rate and a number of long-term survivors in patients with MYCN amplification (Kawa et al, 1999). For infantile neuroblastomas, another group study was started in 1994, and the protocol was revised in 1998 (Matsumura and Michon, 2000).

The INSS is a surgicopathologic staging system and the chief difference between it and the Evans staging system is the definition of stage of locoregional disease (Evans et al, 1971; Brodeur et al, 

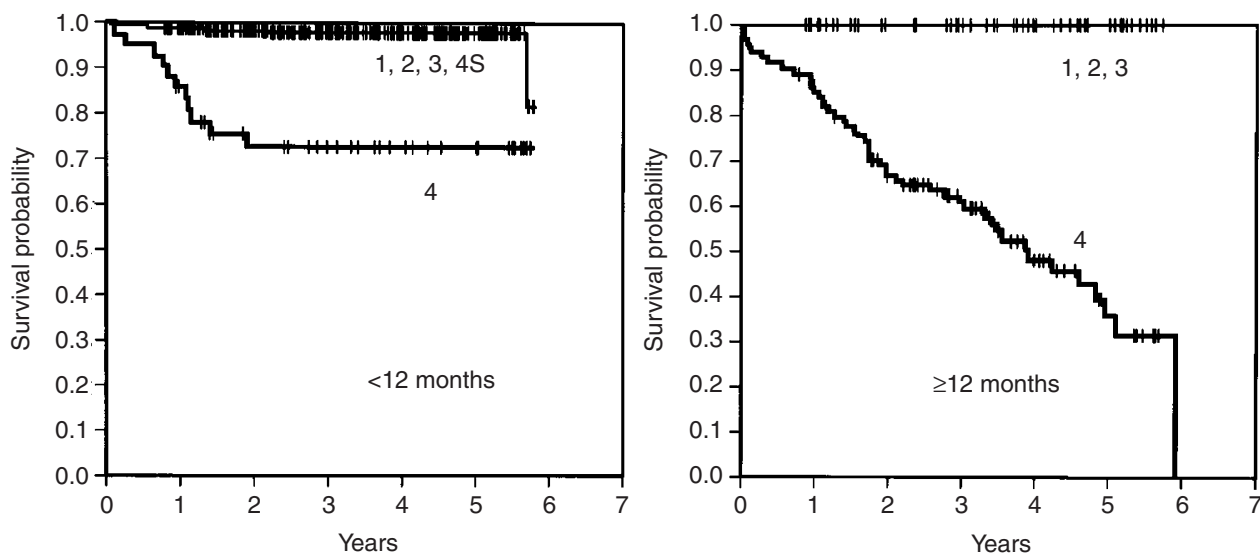

Figure I Cumulated overall survival rates are shown. In patients $<12$ months of age, the 2 - and 4-year overall survival rates for patients in stages I, $2 A$, $2 \mathrm{~B}, 3$ and $4 \mathrm{~S}$ combined $(n=437$ ) were 98.8 and $98.5 \%$, respectively, which were significantly higher than the 73.1 and $73.1 \%$ for patients in stage 4 ( $n=43$ ) $(P<0.000 \mathrm{I})$. In patients $\geqslant 12$ months of age, the 2 - and 4 -OS rates for patients in I, 2A, 2B and 3 stages combined $(n=53)$ were 100 and $100 \%$, while those for patients in stage $4(n=106)$ were 67.3 and $48.5 \%$, respectively $(P<0.000 I)$.
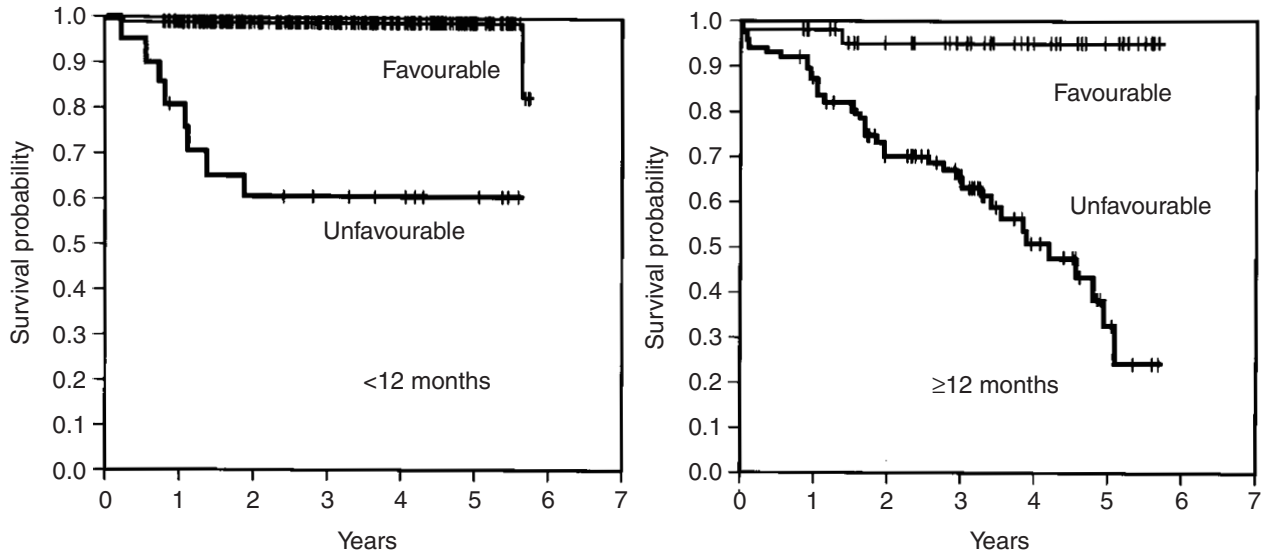

Figure 2 Cumulated overall survival rates for patients $<12$ months of age and $\geqslant 12$ months of age are shown. The 2-and 4-OS rates for patients with favourable histology $(n=402)$ were 98.8 and $98.8 \%$, respectively, significantly higher than the rates of 60.7 and $60.7 \%$ for patients with unfavourable histology $(n=2 \mathrm{I})$ when the patients were $<12$ months of age $(P<0.000 \mathrm{I})$. The 2 - and 4 -OS rates for patients with favourable histology $(n=47)$ were 95.3 and $95.3 \%$, respectively, significantly higher than the corresponding rates of 70.3 and $50.6 \%$ for patients with unfavourable histology $(n=86)$ in patients $\geqslant 12$ months of age $(P<0.000 \mathrm{I})$

Table 4 Multivariate Cox regression analysis of 460 neuroblastoma patients with complete data on age, stage, histology, MYCN status and DNA ploidy

\begin{tabular}{lccc}
\hline Factor & $\mathbf{E x p ( B )}$ & $\mathbf{9 5 \%} \mathbf{C l}$ & $\mathbf{P}$ \\
\hline Age ( $\geqslant 12$ months vs $<12$ months) & 0.78 & $0.34-1.75$ & 0.5431 \\
INSS (4 vs others) & 10.26 & $2.99-35.25$ & 0.0002 \\
INPC (unfavourable vs favourable) & 5.79 & $1.69-19.76$ & 0.0051 \\
MYCN ( 10 copies vs < 10 copies) & 1.40 & $0.68-2.89$ & 0.3642 \\
DNA ploidy (diploidy vs aneuploidy) & 0.83 & $0.39-1.74$ & 0.6185 \\
\hline
\end{tabular}

$\mathrm{Cl}=$ confidence interval; INSS=International Neuroblastoma Staging System; INPC=International Neuroblastoma Pathology Classification. Values are determined by multivariate analysis with the Cox regression models.

1993), but the present study showed that there was no significant difference in survival rate between the stages of localised disease. The 4-OS rate for patients $<12$ months of age with stages 1 , $2 \mathrm{~A}, 2 \mathrm{~B}, 3$ and $4 \mathrm{~S}$ disease was $98.5 \%$ and that for patients $\geqslant 12$ months with stages $1,2 \mathrm{~A}, 2 \mathrm{~B}$ and 3 disease was $100 \%$ (Table 3 ).
On the other hand, the survival rate in patients with metastatic disease (excluding stage 4 S) was significantly worse than in patients with non-metastatic disease, as reported by others (Hero et al, 2000). Previously, differences in survival rates among individual stages were clear (Breslow and McCann, 1971; Matthay et al, 1998). Breslow and McCann (1971) demonstrated that the prognosis for children with neuroblastoma becomes worse in the order stage I, stage IVS, stage II, stage III and stage IV, with coefficients of $1.684,0.661,0.431,-0.092$ and -2.684 , respectively. Matthay et al (1998) found that the survival rate for stage III patients $\geqslant 12$ months of age treated between 1991 and 1995 was still worse than for stage III patients $<12$ months of age $(P=0.01)$. Our follow-up period is shorter than in other studies, and the number of patients in the older age group was rather small; especially there being only 15 patients $\geqslant 12$ months of age with stage 3 disease in the present study, which indicated that there was no difference in the survival rate between stage 3 disease and combined stages $1,2 \mathrm{~A}$ and $2 \mathrm{~B}$ disease in patients $\geqslant 12$ months of age treated between 1995 and 1999. Among these 15 patients $\geqslant 12$ months of age in stage 3, there were five patients with unfavourable INPC and two patients with MYCN amplification. One 

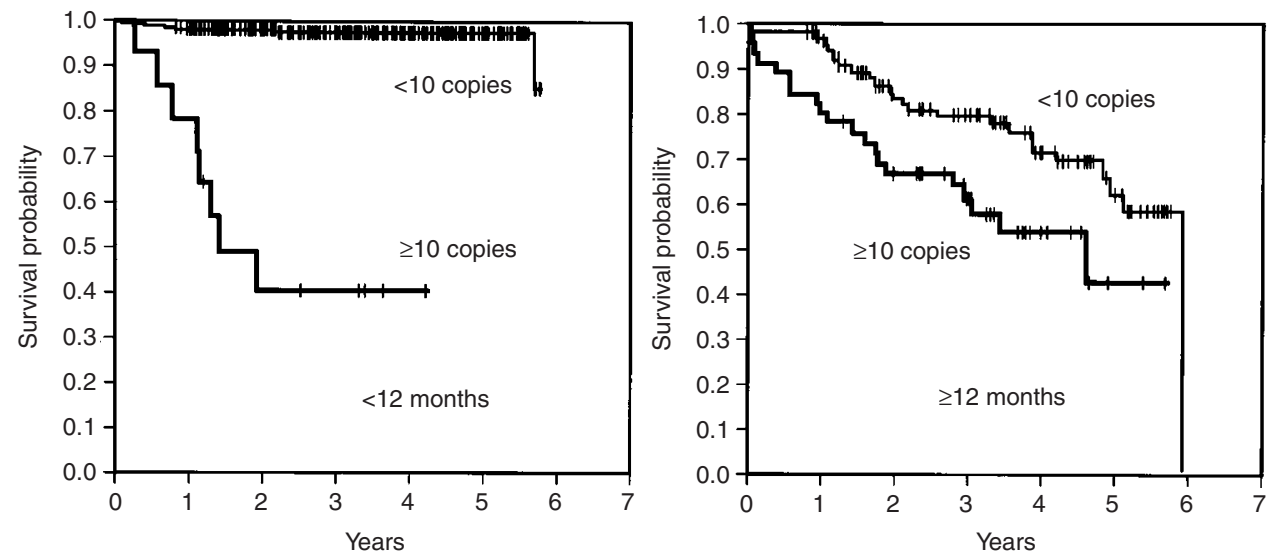

Figure 3 Cumulated overall survival rates for patients $<12$ months of age and $\geqslant 12$ months of age are shown. Among patients $<12$ months of age, the 2- and 4-year overall survival rates for patients with $<10$ copies of MYCN $(n=443)$ were 98.2 and $97.9 \%$, respectively, which were significantly higher than the 40.8 and $40.8 \%$ for patients with $\geqslant 10$ copies of MYCN $(n=14)(P<0.0001)$. In patients $\geqslant 12$ months of age, the 2-and 4-OS rates for patients with $<10$ copies of MYCN $(n=106)$ were 83.8 and $72.0 \%$, respectively, whereas those of patients with $\geqslant 10$ copies of MYCN $(n=46)$ were 67.1 and $54.4 \%$, respectively $(P=0.0117)$
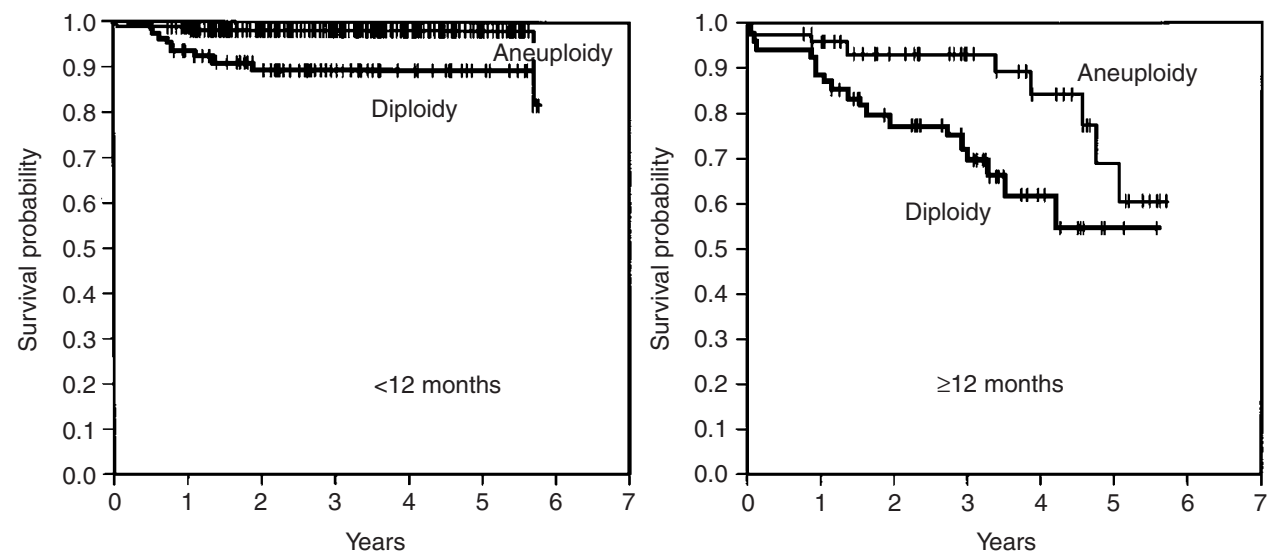

Figure 4 Cumulated overall survival rates for patients $<12$ months of age and $\geqslant 12$ months of age are shown. Among patients $<12$ months of age, the 2- and 4-year overall survival rates for patients with aneuploidy $(n=297)$ were 98.0 and $98.0 \%$, respectively, which were significantly higher than the 89.2 and $89.2 \%$ for patients with diploidy $(n=78)(P=0.0007)$. In patients $\geqslant 12$ months of age, the 2 - and 4-OS rates for patients with aneuploidy $(n=50)$ were 93.4 and $84.2 \%$, respectively, while those for patients with diploidy $(n=55)$ were 77.4 and $61.5 \%$, respectively $(P=0.0256)$.
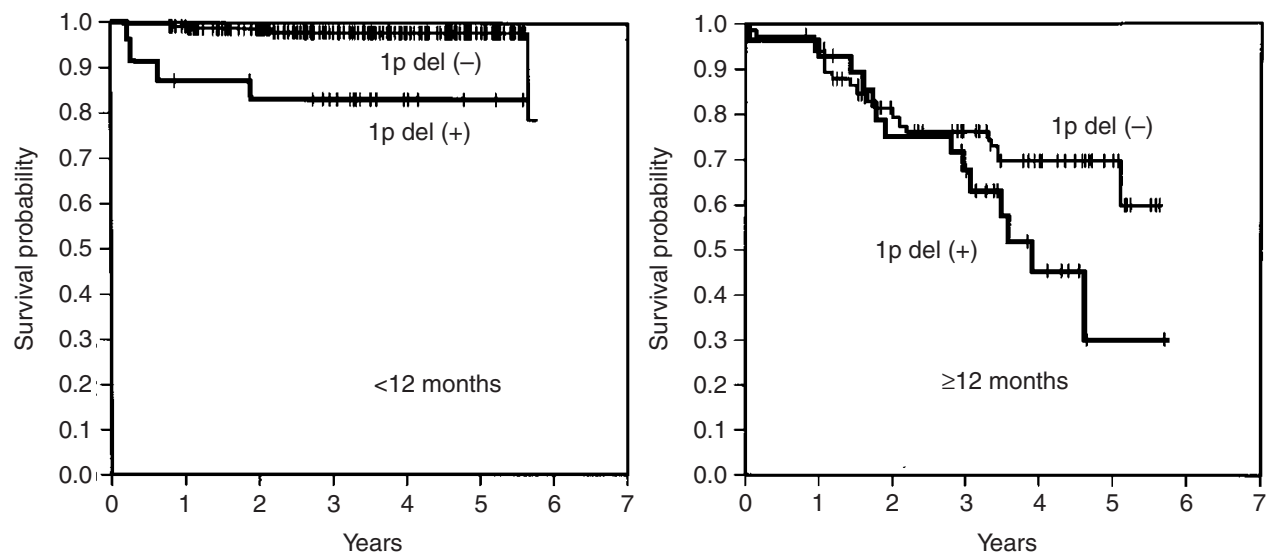

Figure 5 Cumulated overall survival rates for patients $<12$ months of age and $\geqslant 12$ months of age are shown. Among patients $<12$ months of age, the 2- and 4-year overall survival rates for patients without I p deletion $(n=238)$ were 99.2 and $98.6 \%$, respectively, which were significantly higher than the 82.9 and $82.9 \%$ for patients with I $p$ deletion $(n=24)(P<0.000 \mathrm{I})$. In patients $\geqslant 12$ months of age, the 2 - and 4 -OS rates for patients without I $p$ deletion $(n=70)$ were 79.6 and $70.1 \%$, respectively, whereas those for patients with it $(n=29)$ were 75.2 and $42.5 \%$, respectively $(P=0.1$ I 48$)$. 
patient was surviving for 33 months with disease but the remaining 14 were disease free. We therefore would like to consider that this implies some progress in treatment.

The INPC (Shimada et al, 1999) distinguished prognostic groups clearly. Previous studies showed that the histological group provides additional prognostic information beyond factors such as age, stage and MYCN oncogene status (Suita et al, 1994; Rubie et al, 1997; Matthay et al, 1998). The results of this study indicate that INPC histology is a powerful and independent predictor of prognosis.

MYCN amplification in neuroblastoma is associated with advanced stage, rapid tumour progression and poor prognosis (Seeger et al, 1985; Suita et al, 1994; Combaret et al, 1996). Nevertheless, there is controversy over the prognostic importance of $M Y C N$ in localised neuroblastoma. For example, it was shown that patients who have stage 2 neuroblastoma with $M Y C N$ amplification are at higher risk than those without it (Rubie et al, 1997; Alvarado et al, 2000; Perez et al, 2000), but another study demonstrated that the presence of $M Y C N$ amplification in localised neuroblastoma does not necessarily indicate an adverse outcome (Cohn et al, 1995). In the present study, the presence of MYCN amplification was a significant predictor of poor prognosis both in patients $<12$ months and $\geqslant 12$ months of age. Eight of 14 patients with MYCN amplification died within 2 years after diagnosis in the group of patients $<12$ months of age, and the 4-OS rate of patients with $M Y C N$ amplification was only $54.4 \%$ in the patients $\geqslant 12$ months of age, whereas the 4 -OS rate was $72.0 \%$ in patients without MYCN amplification in the same age group. Nevertheless, multivariate analysis showed that MYCN amplification is not an independent prognostic factor. The lack of significance of MYCN amplification as an independent prognostic factor is certainly associated with improved survival for patients with MYCN amplification that was achieved by stratification of treatment with high-dose chemotherapy and blood stem cell transplantation (Kawa et al, 1999). It shows, perhaps, that there was some success with the treatment approach, not that $M Y C N$ has lost importance as a prognostic factor.

DNA ploidy has been considered to be another significant prognostic predictor (Look et al, 1991), but the difference in survival between the patients with diploid tumours and those with aneuploid tumours was not great. The 4-OS rates in patients with aneuploid tumours and with diploid tumours were 98.0 and $89.2 \%$, respectively, among patients $<12$ months of age, and 84.2 and $61.5 \%$, respectively, in patients $\geqslant 12$ months of age. These results appear to support the findings of Look and associates (Look et al, 1991) that demonstrated a close correlation between tumour ploidy and outcome in a large series of patients $<24$ months of age, but not in older patients with metastatic neuroblastoma.

$1 p$ deletion was a significant predictor of prognosis in our patients $<12$ months of age, but not in patients $\geqslant 12$ months. This result is comparable to the results from a study (Maris et al, 2000) in which $\mathrm{LOH}$ at $1 \mathrm{p} 36$ predicted progression free survival, but not decreased overall survival in patients with single copy of MYCN. Tumour suppressor genes responsible for the development of neuroblastoma are assumed to be present on chromosome 1p36, but no conclusive results on the identification and location of such genes for LOH analysis have yet been reported. In this study, 1p deletion was defined when either karyotype analysis or screening for 1 p36 LOH (Ohtsu et al, 1997) showed such deletions as described above. Important genetic abnormalities might not have been detected, which in turn would have affected survival analysis.

A number of factors that correlate with the response to treatment and outcome of patients with neuroblastoma have been identified, including patient age, stage, histology, MYCN amplification, DNA ploidy, 1p deletions, 17q gain (Meddeb et al, 1996; Bown et al, 1999), TRKA expression (Nakagawara et al, 1993; Suzuki et al, 1993) and CD44 cell-surface expression (Combaret et al, 1996). This study evaluated the prognostic importance of the first six factors that are generally considered essential in decision making for treatment, and found that INSS and INPC were significant and independent predictors of prognosis in patients who underwent stratification of treatment. The study included not only patients with clinically detected neuroblastoma but also those identified by mass screening. In Japan, nearly $70 \%$ of neuroblastomas are detected by screening, usually at the age of 6 to 9 months (Tsuchida et al, 2000), hence the high incidence of infantile neuroblastoma in the present study, and the data were analysed thoroughly in the two age groups.

\section{ACKNOWLEDGEMENTS}

The authors thank Ms C Yenches and Mr Ray Cowan for editorial assistance. This work was supported by a grant-in-aid for cancer research (no. 9-14) from the Ministry of Health, Labour and Welfare of the Government of Japan. This work was presented, in part, at the 48th International Congress of the British Association of Paediatric Surgeons, July 2001, London, England and the 33rd Meeting of the International Society of Pediatric Oncology, October 2001, Brisbane, Australia.

\section{REFERENCES}

Alvarado CS, London WB, Look AT, Brodeur GM, Altmiller DH, Thorner PS, Joshi VV, Rowe ST, Nash MB, Smith EL, Castleberry RP, Cohn SL (2000) Natural history and biology of stage A neuroblastoma: a Pediatric Oncology Group Study. J Pediatr Hematol Oncol 22: 197-205

Bown N, Cotterill S, Lastowska M, O’Neill S, Pearson ADJ, Plantaz D, Meddeb M, Danglot G, Brinkschmidt C, Christiansen H, Laureys G, Speleman F (1999) Gain of chromosome arm 17q and adverse outcome in patients with neuroblastoma. $N$ Engl J Med 340: 1954-1961

Breslow N, McCann B (1971) Statistical estimation of prognosis for children with neuroblastoma. Cancer Res 31: 2098-2103

Brodeur GM, Seeger RC, Schwab M, Varmus HE, Bishop JM (1984) Amplification of $\mathrm{N}$-myc in untreated human neuroblastomas correlates with advanced disease stage. Science 224: $1121-1124$

Brodeur GM, Pritchard J, Berthold F, Carsen NLT, Castel V, Castleberry RP, de Bernardi B, Evans AE, Favrot M, Hedborg F, Kaneko M, Kemshead J, Lampert F, Lee REJ, Look AT, Pearson ADJ, Philip T, Roald B, Sawada T, Seeger RC, Tsuchida Y, Voute PA (1993) Revisions of the international criteria for neuroblastoma diagnosis, staging, and response to treatment. $J$ Clin Oncol 11: 1466-1477
Castleberry RP, Shuster JJ, Smith EI (1994) The Pediatric Oncology Group experience with the international staging system criteria for neuroblastoma. J Clin Oncol 12: 2378-2381

Cohn SL, Look AT, Joshi VV, Holbrook T, Salwen H, Changnovich D, Chesler I, Rowe S, Valentine MB, Komuro H, Castleberry RC, Bowman LC, Rao PV, Seeger RC, Brodeur GM (1995) Lack of correlation of N-myc gene amplification with prognosis in localized neuroblastoma: a Pediatric Oncology Group Study. Cancer Res 55: $721-726$

Combaret V, Gross N, Lasset C, Frappaz D, Peruisseau G, Philip T, Beck D, Favrot MC (1996) Clinical relevance of CD44 cell-surface expression and $\mathrm{N}$-myc gene amplification in a multicentric analysis of 121 pediatric neuroblastomas. J Clin Oncol 14: $25-34$

Evans AE, D’Angio GJ, Randolph JA (1971) A proposed staging for children with neuroblastoma. Cancer 27: $374-378$

Hero B, Simon T, Horz S, Berthold F (2000) Metastatic neuroblastoma in infancy: what does the pattern of metastases contribute to prognosis? Med Pediatr Oncol 35: 683-687 
Kaneko M, Nishihira H, Mugishima H, Ohnuma N, Nakada K, Kawa K, Fukuzawa M, Suita S, Sera Y, Tsuchida Y (1998) Stratification of treatment of stage 4 neuroblastoma patients based on N-myc amplification status. Med Pediatr Oncol 31: 1-7

Kaneko M, Tsuchida Y, Mugishima H, Ohnuma N, Yamamoto K, Kawa K, Iwafuchi M, Sawada T, Suita S (2002) Intensified chemotherapy increases the survival rates in patients with stage 4 neuroblastoma with $M Y C N$ amplification. J Pediatr Hematol Oncol (in press)

Kawa K, Ohnuma N, Kaneko M, Yamamoto K, Etoh T, Mugishima H, Ohhira M, Yokoyama J, Bessho F, Honna T, Yoshizawa J, Nakada K, Iwafuchi M, Nozaki T, Mimaya J, Sawada T, Nakamura T, Miyata H, Yamato K, Tsuchida Y (1999) Long-term survivors of advanced neuroblastoma with MYCN amplification. J Clin Oncol 17: 3216-3220

Look AT, Hayes FA, Shuster JJ, Douglass EC, Smith EI, Brodeur GM (1991) Clinical relevance of tumor cell ploidy and N-myc gene amplification in childhood neuroblastoma: a Pediatric Oncology Group Study. J Clin Oncol 9: $581-591$

Maris JM, Weiss MJ, Guo C, Gerbing RB, Stram DO, White PS, Hogarty MD, Sulman EP, Thompson PM, Lukens JN, Matthay KK, Seeger RC, Brodeur GM (2000) Loss of heterozygosity at 1 p36 independently predicts for disease progression but not decreased overall survival probability in neuroblastoma patients: a Children's Cancer Group Study. J Clin Oncol 18: $1888-1899$

Matsumura T, Michon J (2000) Treatment of localized neuroblastoma. In Neuroblastoma Brodeur GM, Sawada T, Tsuchida Y and Voûte PA (eds) pp 403-415, Amsterdam: Elsevier

Matthay KK, Perez C, Seeger RC, Brodeur GM, Shimada H, Atkinson JB, Black CT, Gerbing R, Haase GM, Stram DO, Swift P, Lukens JN (1998) Successful treatment for stage III neuroblastoma based on prospective biologic staging: a Children's Cancer Group Study. J Clin Oncol 16: $1256-1264$

Matthay KK, Villablanca JG, Seeger RC, Stram DO, Harris RE, Ramsay NK, Swift P, Shimada H, Black CT, Brodeur GM, Gerbing RB, Reynolds CP (1999) Treatment of high-risk neuroblastoma with intensive chemotherapy, radiotherapy, autologous bone marrow transplantation, and 13-cisretinoic acid. $N$ Engl J Med 341: 1165-1173

Meddeb M, Danglot G, Chundoba I, Venuat AM, Benard J, Avet-Loiseau H, Vasseur B, Le Paslier D, Terrier-Lacombe MJ, Hartmann O, Bernheim A (1996) Additional copies of a $25 \mathrm{Mb}$ chromosomal region originating from $17 \mathrm{q} 23.1-17 \mathrm{qter}$ are present in $90 \%$ of high-grade neuroblastomas. Genes Chromosomes Cancer 17: 156-165

Nakagawara A, Arima-Nakagawara M, Scavarda NJ, Azar CG, Cantor AB, Brodeur GM (1993) Association between high levels of expression of the TRK gene and favourable outcome in human neuroblastoma. $N$ Engl $J$ Med 328: $847-854$

\section{Appendix-Participating institutions chief investigators}

Gunma Children's Medical Center, Gunma (Tsuchida Y, Kuroiwa M); Kyoto Prefectural University of Medicine, Kyoto (Iehara T, Sugimoto T, Sawada T); University of Tsukuba, Tsukuba (Kaneko M); Keio University, Tokyo (Hata J); Dokkyo University, Koshigaya (Ikeda H); National Sapporo Hospital, Sapporo (Naito H); Hokkaido University, Sapporo (Sasaki F); Yamagata University, Yamagata (Mitsui T); Fukushima Medical University, Fukushima (Kikuta A); Niigata University, Niigata (Iwafuchi M, Kaneda S); Ibaraki Children's Hospital, Mito (Kenmotsu H); Jichi Medical School, Tochigi (Itonaga N); Saitama Children's Medical Center, Iwatsuki (Yamamoto K), Saitama Medical School, Saitama (Shibuya A); National Defense Medical College, Tokorozawa (Sekine I); Chiba University, Chiba (Ohnuma $\mathrm{N}$, Matsunaga M); Chiba Children's Hospital, Chiba (Etoh T); Nihon University, Tokyo (Mugishima H); University of Tokyo, Tokyo (Kobayashi M); National Children's Hospital, Tokyo (Kumagai M); Juntendo University, Tokyo (Fujita H); Showa University, Tokyo (Tanaka D); Jikei University, Tokyo (Yamazaki Y); St. Luke's International Hospital, Tokyo (Hosoya R); Kiyose Metropolitan Children's Hospital, Kiyose (Hayashi A Hirobe S); Hachioji Metropolitan Children's Hospital, Hachioji (Nishina T); Kanagawa Children's Medical Center, Yokohama (Toyoda Y); St. Marianna University, Kawasaki (Nakada K); Kitasato University, Sagami-
Ohtsu K, Hiyama E, Ichikawa T, Matsuura Y, Yokoyama T (1997) Clinical investigation of neuroblastoma with partial deletion in the short arm of chromosome 1. Clin Cancer Res 3: 1221-1228

Perez CA, Matthay KK, Atkinson JB, Seeger RC, Shimada H, Haase GM, Stram DO, Gerbing RB, Lukens JN (2000) Biologic variables in the outcome of stages I and II neuroblastoma treated with surgery as primary therapy: a Children's Cancer Group Study. J Clin Oncol 18: 18-26

Rubie H, Hartmann O, Michon J, Frappaz D, Coze C, Chastagner P, Baranzelli MC, Plantaz D, Avet-Loiseau H, Benard J, Delattre O, Favrot M, Peyroulet MC, Thyss A, Perel Y, Bergeron C, Courbon-Collet B, Vannier JP, Lemerle J, Sommelet D (1997) N-Myc gene amplification is a major prognostic factor in localized neuroblastoma: results of the French NBL 90 Study. J Clin Oncol 15: 1171-1182

Sawaguchi S, Kaneko M, Uchino J, Takeda T, Iwafuchi M, Matsuyama S, Takahashi H, Nakajo T, Hoshi Y, Okabe I, Yokoyama J, Nishihira H, Sasaki S, Sakurai M, Sawada T, Nagahara N, Tsuchida Y (1990) Treatment of advanced neuroblastoma with emphasis on intensive induction chemotherapy: a report from the Study Group of Japan. Cancer 66: $1879-1887$

Seeger RC, Brodeur GM, Sather H, Dalton A, Siegel SE, Wong KY, Hammond D (1985) Association of multiple copies of the N-myc oncogene with rapid progression of neuroblastomas. $N$ Engl J Med 313: $1111-1116$

Shimada H, Ambros IM, Dehner LP, Hata J, Joshi VV, Roald B, Stram DO, Gerbing RB, Lukens JN, Matthay KK, Castleberry RP (1999) The International Neuroblastoma Pathology Classification (the Shimada System). Cancer 86: $364-372$

Suita S, Zaizen Y, Kaneko M, Uchino J, Takeda T, Iwafuchi M, Utsumi J, Takahashi H, Yokoyama J, Nishihira H, Okada A, Kawa K, Nagahara N, Yano H, Tsuchida Y (1994) What is the benefit from aggressive chemotherapy for advanced neuroblastoma with N-myc amplification? A report from the Japanese Study Group for Treatment of Advanced Neuroblastoma. J Pediatr Surg 29: 746-750

Suzuki T, Bogenmann E, Shimada H, Stram D, Seeger RC (1993) Lack of high-affinity nerve growth factor receptors in aggressive neuroblastomas. $J$ Natl Cancer Inst 85: 337-348

Tsuchida Y, Ikeda H, Shitara T, Tanimura M (2000) Evaluation of the results of neuroblastoma screening at six months of age. Med Pediatr Oncol 34: $80-81$

hara (Nakadate H); Tokai University, Isehara (Yokoyama S); Shizuoka Children's Hospital, Shizuoka (Hamazaki M, Mimaya J, Horigoshi Y); Gifu City Hospital, Gifu (Takao A); Kanazawa Medical University, Ishikawa (Kawano M); Fukui Medical University, Fukui (Yazawa A); Nagoya City University, Nagoya (Kondo S); Mie University, Tsu (Komada Y, Hirayama M, Hori H); Shiga University of Medical Science, Ohtsu (Ohta S); Osaka Medical Center for Maternal and Child Health, Izumi (Kawa K, Inoue M, Yoneda M, Oue T); Osaka University, Suita (Okada A, Kusafuka T); Osaka City Medical Center, Osaka (Nakamura T); Kinki University, Sakai (Miyata H); Okayama University, Okayama (Nishiuchi R); Hiroshima University, Hiroshima (Hiyama E); National Kure Hospital, Kure (Tanaka T); Yamaguchi University, Ube (Ayukawa H); Tokuyama Hospital, Tokuyama (Uchida M); Kagawa Children's Hospital, Zentsuji (Iwai T); Ehime University, Ehime (Ishida Y); Ehime Prefectural Hospital, Matsuyama (Oofuji Y); Kochi Medical University, Nangoku (Wakiguchi H); Kochi Prefectural Hospital, Kochi (Yoshikawa K); Kyushu University, Fukuoka (Suita S); National Kyushu Cancer Center, Fukuoka (Okamura J); Saga Medical University, Saga (Miyazaki S, Koga H); Oita Medical University, Oita (Suenobu S); Miyazaki Medical University, Miyazaki (Kuroda H); Kagoshima University, Kagoshima (Takamatsu H, Fukushige T). 